\title{
Socio-cultural Factors Influencing Adherence to Antiretroviral Therapy Among People Living with HIVIAIDS in a Tertiary Hospital in Southwestern Nigeria
}

\author{
Okunola Oluseye Ademola ${ }^{1}$, Muoghalu Caroline ${ }^{1}$, Irinoye Adedayo Ishola ${ }^{2}$ \\ ${ }^{1}$ Sociology and Anthropology Department, Obafemi Awolowo University, Ile-Ife, Nigeria \\ ${ }^{2}$ Medical and Health Services, Obafemi Awolowo University, Ile-Ife, Nigeria \\ Email address: \\ oaokunola@oauife.edu.ng (O. O. Ademola)
}

\section{To cite this article:}

Okunola Oluseye Ademola, Muoghalu Caroline, Irinoye Adedayo Ishola. Socio-cultural Factors Influencing Adherence to Antiretroviral Therapy Among People Living with HIV/AIDS in a Tertiary Hospital in Southwestern Nigeria. International Journal of HIV/AIDS Prevention, Education and Behavioural Science. Vol. 5, No. 2, 2019, pp. 124-133. doi: 10.11648/j.ijhpebs.20190502.17

Received: August 22, 2019; Accepted: September 24, 2019; Published: November 8, 2019

\begin{abstract}
The study investigated the socio-cultural factors influencing adherence to antiretroviral drugs among people living with HIV in a University Teaching Hospital in South-western Nigeria. It investigated the influence of various socio-cultural factors on adherence of PLWHA to treatment regimen People Living with HIV/AIDS (PLWHA) of antiretroviral therapy (ART) in Obafemi Awolowo University Teaching Hospitals Complex, Ile-Ife and assessed the prevalence of adherence to ART among PLWHA in the study area. These were with the view to ascertaining the influence of socio-cultural factors in the PLWHA's adherence to antiretroviral therapy in the study location. The study design was a cross-sectional where both qualitative and quantitative research methods were adopted. The quantitative data were collected using structured questionnaire. The participants were HIV diagnosed patients attending clinic at the Obafemi Awolowo University Teaching Hospitals Complex in Ile-Ife where ages were between 18 and 60 years. Also two focus group discussion sessions were held with 10 males and 10 females living with HIV and currently on ART. Furthermore, in-depth interviews were conducted on three purposively selected healthcare givers (an experienced nurse, a doctor and a pharmacist) in the clinic. The quantitative data were analyzed using descriptive statistics such as tables and percentages and inferential statistics such as Chi Square and cross-tabulations. The qualitative data were analyzed in themes based on the objectives. The findings from the study indicated level of adherence to ART was $89.0 \%$ among the respondents. There was a statistically significant relationship $\left(\chi^{2}=22.14 ; p<0.01\right)$ between social and family supports and the degree of adherence to ART among PLWHA. There was a statistically significant relationship between level of adherence and respondents' age $\left(\chi^{2}=66.05, p<0.05\right)$. The older the respondents' age, the higher the level of adherence to ART. Also the relationship between educational level and adherence to ART was explored and found to be statistically significant $\left(\chi^{2}=26.04, p<0.05\right)$. Adherence is inversely proportional to educational attainment. Nutrition, polygyny, difficulty in financing transportation fare to the clinic, unemployment, drug hawkers, religion, excuse duty from work and waking up very early were highlighted as socio-cultural barriers to adherence to ART. Fear of death, strong family support, religious belief, not seeking alternative treatment, absence of rituals and perceived improved health status were identified as very strong facilitators to adherence. The study concluded that socio-cultural factors exert very strong influences on PLWHA's adherence to antiretroviral therapy.
\end{abstract}

Keywords: Antiretroviral Therapy, HIV/AIDS, Adherence, Socio-cultural

\section{Introduction}

The scourge of Human Immunodeficiency Virus / Acquired Immunodeficiency Diseases (HIV/AIDS) with the development of antiretroviral drugs in its management has gone a long way to make it a chronic manageable disease. However, strict adherence is required to achieve therapeutic success in HIV management. Nigeria has the third largest infected population (2-3.2 million) of People Living With HIV/AIDS (PLWHA) in the world after South Africa and 
India [1]. Human Immunodeficiency Virus (HIV) affected 37.9 million people globally million of which 36.2 million are adults worldwide as at the end of 2018 [1]. Sub-Saharan Africa with just over $10 \%$ of the world's population has the greatest burden of disease (65\%). In the year 2018, 2.6 million people had access to antiretroviral treatment which represents 51\% of PLWHA accessing ART. [1]

Nigeria third among the countries with the highest HIV/AIDS burden in the world, next only to India and South Africa. There is therefore the need for concerted efforts toward tackling this menace. The development and widespread use of antiretroviral therapy (ART) as the treatment of choice in HIV has improved significantly the health conditions of HIV positive individuals who could have untimely death. The ART however, has transformed the perception of HIV/AIDS from a fatal incurable disease to a manageable chronic illness [2]. The treatment causes improvement in immunologic status and reduction in the viral load [3] which consequently reduces the incidence of hospitalization and mortality [4].

However, incomplete medication adherence is the most important factor in treatment failure and the development of resistance. Adherence is the term used to describe the patient's behaviour of taking drugs correctly in the right dose, with the right frequency and at the right time. Antiretroviral treatment success depends on sustainable high rates of adherence to medication regimen of ART [5]. On the other hand, ART regimens are habitually complicated with variable dosage schedules, dietary requirements and adverse effects [6]. Treatment success can be precarious with missing of few doses of antiretroviral medication which leads to drug resistant strains of HIV [7]. An adherent patient is defined as one who takes $95 \%$ of the prescribed doses on time and in the correct way, either with or without food. Adherence is a major predictor of the survival of individuals living with HIV/AIDS [8] and poor adherence to treatment remains a major obstacle in the fight against HIV/AIDS worldwide. Low or incomplete medication adherence has been associated with detectable viral load ( $>500$ viral RNA copies/ ml of plasma) (Ruthbun, Farmer, Stephens, \& Lockhard, 2005) with the development of cross resistance to other antiretroviral of the same class (Tchetgen, Kaplan, \& Friendland, 2001). Although, more potent antiretroviral regimens can allow for effective viral suppression at moderate levels of adherence [9], none or partial adherence can lead to the development of drug-resistant strains of the virus. Cross-resistance however can potentially interfere with future therapeutic regimens for HIV- infected patients undergoing treatment and for those who subsequently become infected with resistant strains of HIV [9].

Several studies on ART adherence [7, 10, 11] had largely focused on the extent of adherence, knowledge and attitude, little attention was paid to associated socio-cultural factors that could pre-suppose adherence. The existence of various studies on the barriers to drug adherence among PLWHA notwithstanding; identifying the social and cultural factors influencing non-adherence to drug among PLWHA as stringent compliance to medication remains a very strong determinant of patients' management outcome have not been given adequate attention. Several researchers have tried to look at those factors ranging from socio-economic issues, environmental factors, and patient-doctor's interaction among PLWHA affecting their adherence, but not much attention have been paid to the influence of social and cultural factors simultaneously on this issue. This is the gap that this research intends to fill. As such adherence level of ART and socio-cultural factors will be addressed.

\section{Objectives}

The general objective of this study is to examine the various social and cultural factors hindering adherence to antiretroviral drugs of PLWHA in OAUTHC, Ile-Ife. The specific objectives are to:

1. assess the prevalence of adherence to ART among PLWHA in the study area and

2. investigate the influence of socio- cultural factors on adherence to treatment regimen in the study area.

\subsection{Theoretical Framework}

This study combined both Action theory and Information Motivation and Behavioural Skills Model. The theoretical framework for this study is Action Theory which is a sociological perspective that focuses on the individual as a subject. It views social action as something purposively shaped by individuals within a context to which they have given meaning. Action theory approach has its foundations in Max Weber's 'interpretive theory' which claims that it is necessary to know the subjective purpose and intent of the actor before an observer can understand the meaning of social action.

In his action theory, Weber's clear intent was to focus on individuals and patterns and regularities of action. Action in the sense of subjectively understandable orientation of behaviour exists only as the behaviour of one or more individual human beings [12]. Weber argued that sociological explanation of actions should begin with observing and interpreting the subjective inner state of the actor. By subjective inner state, Weber was referring to the capacity of the actors to act on their interpretation, understanding, meaning and judgment, and to exercise rational choice by carrying out their actions with a view to realizing their choice in the society. Thus, Weber made use of the terms interpretation, meaning, understanding and judgment to identify the subjective inner state of an actor that makes $\mathrm{him} /$ her to act the way he/she does.

Max Weber's 'interpretive sociology' claims that it is necessary to know the subjective purpose and intent of the actor before an observer can understand the meaning of social action. From this we can speak of social action insofar as it has a subjective judgment and meaning of the inner state of the actor. If action therefore stems from the subjective inner state of the actor [13], it is imperative to discover those meanings in order to understand and explain the actions of 
the actors. Meaning of an action therefore lies in the specific value consideration of the actor.

Weber further stated that the society is a product of human actions according to values and value end. Thus, whatever is produced in society by human action is the result of the value attached to it. According to Weber, the decision to act in a certain way is always the product of the actor's value, understanding, meaning and interpretative judgment within a given society or social group [14]. This is because our society or social group to which we belong has value system and also has particular views of life. From our social groups we learn the value system and ways of perceiving issues and we structure our action in line with our perception.

\subsection{Information Motivation and Behavioural Skills Model}

The other theoretical framework this study intends using is the Information Motivation and Behavioural Skills Model. The Information motivation, behaviour skills models will be reviewed to discuss adherence to antiretroviral treatment. According to [15], Information-Motivation-Behavioural Skills-Model of adherence assumes that adherence related information, motivation and behavioural skills are critical determinants of adherence to antiretroviral treatment.

The model states that adherence-related information, motivation work through adherence-related behavioural skills to affect adherence to antiretroviral treatment. The implication of this model translates therefore to the extent that HIV patients are well informed, motivated to take action and possess the required behavioural skills to act effectively. substantial health benefit of the treatment. Conversely, poor or non-adherence will occur and health benefit lost when HIV positive patients are poorly informed, motivated to take action and lack the required behavioural skills to act effectively, they will be more likely to adhere to medication regimens over time and in turn derive/experience. This model is of very significant value as a wide range of health related behaviours is linked to the profound influence of three key elements of information, motivation and behavioural skills [15].

\section{Methodology}

\subsection{Study Location}

The study was conducted in the Institute of Human Virology of Nigeria which is situated inside the premises of the teaching hospital in Ile-Ife. It was conducted among the clients currently receiving ART there. This institution has catchment of patients from Ondo, Osun and Ekiti states. The choice of the study location is as a result of the centre being a referral centre and at the same time the only place where ART is being carried out according to the national guideline on management of HIV/AIDS patients in Ile-Ife and its environs. This centre is selected as patients diagnosed of HIV from various neighbouring communities are referred to this centre for management hence having a wide distribution of clients from various zones.

\subsection{Research Design}

The study design was cross-sectional and both qualitative and quantitative research methods were adopted. Adherence was determined based on assessment of six sets of questions on patients taking their medication without missing any drug within the last one week and non-adherence was based upon inconsistency or default in taking the drugs within the last one week.

\subsection{Population and Sample Size}

The study populations were 3007 patients (male and female) between the ages of 18 and 60 years who have been receiving ARV drugs for over six months before the commencement of this study. Pregnant women, children and any other patients with other morbidities were not included in the study.

Sampling size was determined using the formula

$$
\begin{gathered}
\mathrm{n}(\mathrm{f})=\mathrm{n} / 1+(\mathrm{n} / \mathrm{N}) \\
\mathrm{n}=\mathrm{z} 2 \mathrm{pq} / \mathrm{d} 2
\end{gathered}
$$

where $\mathrm{z}=$ standard deviation 1.96 (Fischer 1981)

$\mathrm{p}=$ prevalence of adherence in southwest is $44 \%=0.44$

$\mathrm{q}=$ failure rate $=1-\mathrm{p}=1-0.44=0.56$

$\mathrm{d}=$ level of significance $=0.05$

$\mathrm{N}=$ study population $=3,007$

Hence the sample size calculated is 336. As such 336 copies of questionnaire were administered on respondents. Also three in-depth interviews were conducted with a nurse, a doctor, and a pharmacist.

\subsection{Sampling Technique}

The sample for the study comprised of male and female clients who have been on ART for more than six months and between the ages of 18 to 60 years. One out of every tenth patients was systematically selected as they presented on each clinic days and were recruited until the desired sample size was achieved. These constituted the patients that were administered questionnaires. Furthermore, two focus group discussion sessions were conducted. Each group was made up 10 participants. One group consisted males and the other females. Respondents for questionnaire were purposively selected. This sampling technique was used due to the sensitive nature of the study and only few people fit into the purpose of the study. Patients aged between 18 and 60 years on HAART for more than 6 months were eligible for inclusion.

\subsection{Research Instrument}

The research instruments for this study were comprised of structured questionnaire. Each questionnaire comprised five sections namely, Sections A, B, C, D and E. Section A contained socio-demographic variables. This section was designed to provide information on respondent's sociodemographic variables such as age, sex, marital status among 
others. Section B contained questions on HIV status and knowledge. Section C contained questions on client's perception of ART. Section D contained questions on support network and various socio-cultural factors affecting ART while section assessed adherence to ART. Also interview guide was used to collect with seven sets of questions to assess various socio-cultural factors affecting adherence to ART. Focus group discussion guide was also used to collect information from the respondents. Section A collected information on demographic variables, section was used to assess individual factors affecting ART and section $\mathrm{C}$ collected information on socio-cultural variables. The questionnaires were administered to the respondents at the clinic on their clinic days in the hospital while the interview and focus discussion groups were conducted in the consulting room after the end of the clinic for the day.

\subsection{Method of Data Collection}

Several visits to the clinic and interaction with health workers and PLWHA indicated that there were about 3,000 PLWHA. Staff and patients were favourably disposed to participating in the study.

Data were collected at the clinic by the researcher. In order for the data collection to be hitch free, permission was sought and obtained from the director of the Institute. Structured questionnaire was administered to the respondents. Interviews were conducted with the aid of an interview guide and included probes for further questioning, covering questions on how ART fitted into their daily routines and what the key barriers (social, personal and cultural factors) to adherence to ART were. Also two focus group discussion sessions were conducted for 10 males and 10 females with the aid of the focus group discussion guide. The interviews were conducted and audio-taped by the researcher. Data were collected between May and September 2015.

\subsection{Data Analysis}

The analysis of quantitative data was done in three stages. Firstly, the information obtained from the field was edited; the copies of questionnaire were thoroughly checked to correct all inconsistencies in responses by the respondents. This was done in form of field editing, that is, checking for mistakes and omissions in recording of information while on the field. Secondly, data analysis was preceded by datacoding and data-entry and analysed using Statistical package for social sciences version 20. Data were analysed using descriptive statistics and inferential statistics. The descriptive data were presented in the form of frequency distribution and percentages for inferential statistics, cross-tabulation of some variables and hypotheses, chi-square and regression analysis were employed to test the strength of relationship among the variables. The level of significance was set at $p \leq 0.05$. Information elicited through qualitative data was analysed using content analysis. The data were analysed in themes as each objective formed a theme. The audio responses were transcribed and verbatim quotations were utilized to describe the responses from the qualitative method.

\subsection{Ethical Consideration}

Before the commencement of the study, the purpose of the study was explained to the respondents, assuring them of the confidentiality of their responses and identities. They were also assured that they would not come to any harm as a result of participating in the study. Also their consent was sought and obtained prior to participation. Also, Ethical permission for the study was obtained from the Ethics and Research committee of OAUTHC, Ile-Ife.

\section{Results}

Firstly, univariate analyses presented the sociodemographic characteristics of the respondents using frequency distribution and percentages. The variables presented are sex, age, marital status, ethnic affiliation, religion, level of education, occupation, average monthly income, place of residence and people whom they are residing with. In all, three hundred and thirty-six (336) copies of questionnaire were administered in the clinic but three hundred and twenty-nine (329) were retrieved for analysis. The response rate is about $98 \%$.

\subsection{Relationships Between the Socio-demographic Variables and the Level of Adherence to ART}

Table 1 presented the relationship between level of adherence to ART and socio-demographic variables.

It can be seen from the table that a significant relationship exists between adherence and respondents' age. $\left(\chi^{2}=66.05, \mathrm{p}\right.$ $<0.05)$. Also the data showed that the older the respondents the higher their level of adherence to ART. Majority (62.4\%) of the respondents in the 31 to 40 years age range were found to possess high level $(62.4 \%)$ of adherence to ART than other groups (e.g. $14.3 \%$ for 15 to 30 age bracket). At the very high level of adherence, more $(60.2 \%)$ of the older respondents (41 to $50 \mathrm{yrs}$ of age) feature than younger ones $(27.7 \%$ among 31 to $40 \mathrm{yrs}$ of age). However, at very low level of adherence more of the younger respondents (15 to 30 years of age) featured very prominently $(14.3 \%)$ compared with the other age categories (e.g. $1.4 \%$ among 31 to 40 years age group and $0 \%$ for those in the 41 to $50 \mathrm{yrs}$ age bracket).

Also, the data indicate that the level of adherence is significantly related to the ethnic group of the respondents $\left(\chi^{2}\right.$ $=46.52, \mathrm{p}<0.05)$. All the respondents who demonstrated very high level of adherence are Yoruba (40.8\%), at the high level of adherence, Yoruba also feature prominently (49.7\%) while the Igbo constitute only 25 percent and none of those at high level of adherence from the Hausa ethnic group. All the Hausa in the study were found at the low level of adherence.

The respondents' religion is also significantly related to their level of adherence to ART $\left(\chi^{2}=16.76, p<0.05\right)$. The traditional religion practitioners featured prominently $(50 \%)$ compared with other religious groups. At the very low level of adherence, adherents of the Islam feature more 
prominently $(12.5 \%)$ than the Christian $(1.9 \%)$. When the relationship between educational level and adherence to ART was explored, a significant relationship was found to exist $\left(\chi^{2}\right.$ $=26.04, \mathrm{p}<0.05)$. Adherence is inversely proportional to educational attainment. At the very high level of adherence response with secondary school educational attainments feature most prominently (45.4\%) closely followed by those with post-secondary educational attainment (40.9\%). Most of those with low adherence were post-secondary educational attainment.

Further, a significant relationship exists between adherence with ART and occupation $\left(\chi^{2}=86.66, p<0.05\right)$. Those who were employed in the private sector featured most $(60 \%)$ in the category of those who possess very high level of adherence and are closely followed by artisans (50\%). Public sector workers featured most prominently among those with low level of adherence with ART.

Finally, adherence with ART is also significantly related to whom the respondents live with. Among the respondents in the very high level of adherence group, those who live alone featured most prominently ( $83.3 \%$ ) closely followed by those who live with their children $(42.9 \%)$. Those who live with relative featured very prominently among those with very low level of adherence while those who live with their friends possessed low level of adherence to ART.

Table 1. Relationship between the level of adherence with the socio-demographic variables.

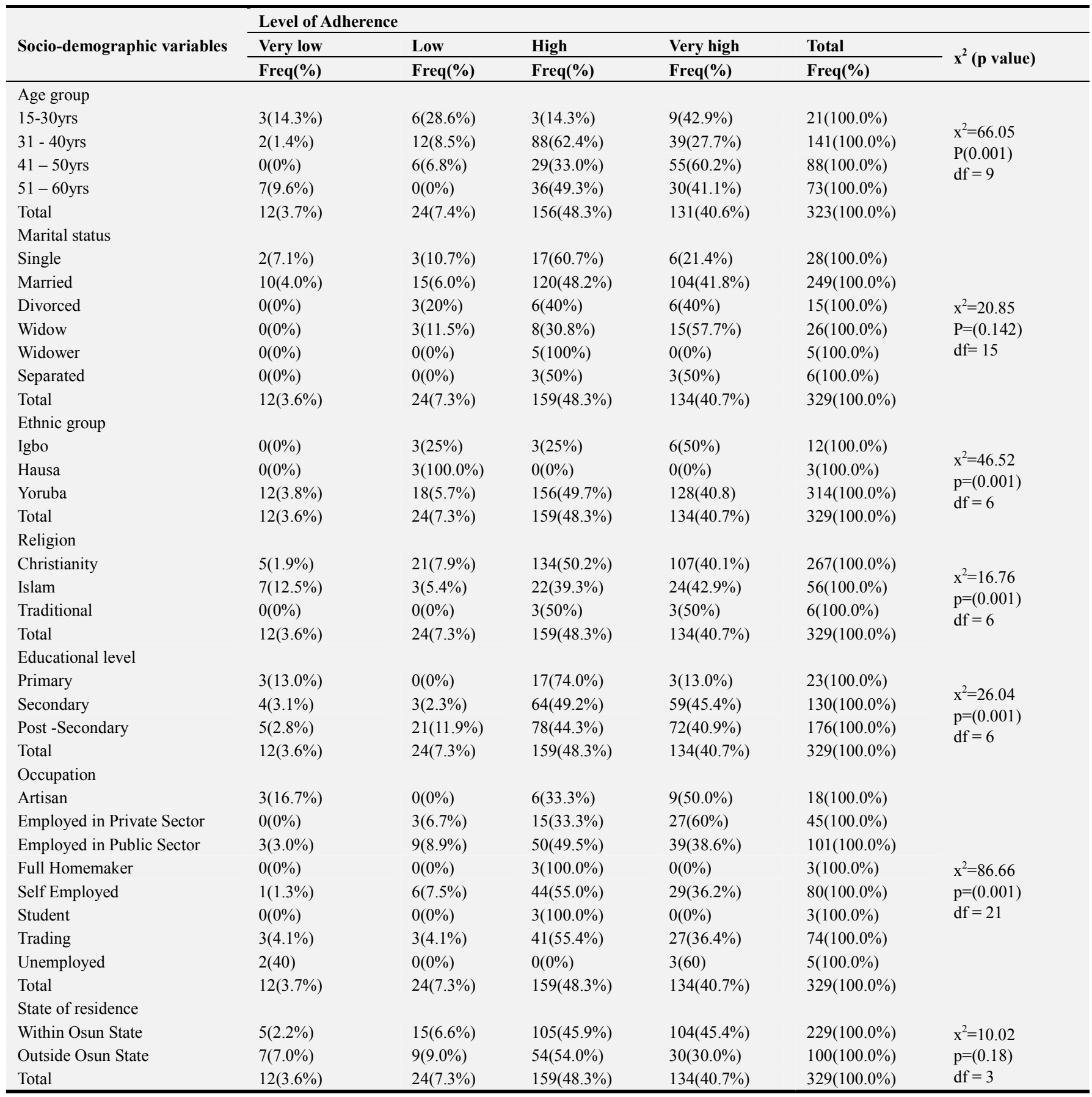




\begin{tabular}{|c|c|c|c|c|c|c|}
\hline \multirow{3}{*}{ Socio-demographic variables } & \multicolumn{6}{|c|}{ Level of Adherence } \\
\hline & Very low & Low & High & Very high & Total & \multirow{2}{*}{$x^{2}$ (p value) } \\
\hline & Freq(\%) & Freq(\%) & Freq(\%) & Freq(\%) & Freq(\%) & \\
\hline \multicolumn{7}{|l|}{ With whom they live } \\
\hline Alone & $0(0 \%)$ & $0(0 \%)$ & $3(16.7 \%)$ & $15(83.3)$ & $18(100.0 \%)$ & \multirow{7}{*}{$\begin{array}{l}x^{2}=110.44 \\
p=(0.001) \\
d f=21\end{array}$} \\
\hline With My Partner & $0(0 \%)$ & $3(13.4 \%)$ & $57(47.8 \%)$ & $83(38.8 \%)$ & $212(100.0 \%)$ & \\
\hline With Parents & $0(0 \%)$ & $0(0 \%)$ & $11(78.6 \%)$ & $3(21.4 \%)$ & $14(100.0 \%)$ & \\
\hline With Relatives & $5(45.4 \%)$ & $0(0 \%)$ & $3(27.3 \%)$ & $3(27.3 \%)$ & $11(100.0 \%)$ & \\
\hline With Friends & $0(0 \%)$ & $3(27.3 \%)$ & $5(45.4 \%)$ & $3(27.3 \%)$ & $11(100.0 \%)$ & \\
\hline With my children & $0(0 \%)$ & $6(9.5 \%)$ & $30(47.6 \%)$ & $27(42.9 \%)$ & $63(100.0 \%)$ & \\
\hline Total & $12(3.6 \%)$ & $24(7.3 \%)$ & $159(48.3 \%)$ & $134(40.7 \%)$ & $329(100.0 \%)$ & \\
\hline \multicolumn{7}{|l|}{ Income group } \\
\hline 5000 to 20000 & $3(3.0 \%)$ & $3(3.0 \%)$ & $42(42.4 \%)$ & $51(51.5 \%)$ & $99(100.0 \%)$ & \multirow{5}{*}{$\begin{array}{l}x^{2}=11.94 \\
p=(0.217) \\
d f=9\end{array}$} \\
\hline 20001 to 40000 & $3(9.1 \%)$ & $0(0 \%)$ & $12(36.4 \%)$ & $18(54.5 \%)$ & $33(100.0 \%)$ & \\
\hline 40001 to 100000 & $0(0 \%)$ & $3(6.3 \%)$ & $27(56.2 \%)$ & $18(37.5 \%)$ & $48(100.0 \%)$ & \\
\hline more than 100000 & $0(0 \%)$ & $0(0 \%)$ & $4(57.1 \%)$ & $3(42.9 \%)$ & $7(100.0 \%)$ & \\
\hline Total & $6(3.2 \%)$ & $6(3.2 \%)$ & $85(45.5 \%)$ & $90(48.1 \%)$ & $187(100.0 \%)$ & \\
\hline
\end{tabular}

\subsection{Respondents Level of Adherence to ART}

Table 2 below presents the distribution of the respondent's level of adherence to ART, it was indicated that $89.0 \%$ of the PLWHA have overall high adherence level to their ART. To measure the respondent's level of adherence as presented in section $\mathrm{E}$ of the questionnaire, the questions were scored such that a 'yes' response was allocated 1 and a 'no' response was scored 0 , negative items were transposed and then the scores were cumulated to constitute a measure of adherence to ART. The scores were categorized in such a way that any score of 3 or less were regarded as 'very low', any score greater than 3 and up to 4 were regarded as 'low', any score greater than 4 and up to 5 were regarded as 'high' and any score greater than 5 and up to 6 were regarded as 'very high'. When asked during the focus group discussions on how many of their doses did they miss in the last one week here are the following excerpts:

Table 2. Respondents Level of Adherence to ART.

\begin{tabular}{lll}
\hline Adherence options & Frequency & Percentage \\
\hline Very low adherence level & 12 & 3.6 \\
Low adherence level & 24 & 7.3 \\
\hline
\end{tabular}

\begin{tabular}{lll}
\hline Adherence options & Frequency & Percentage \\
\hline High adherence level & 159 & 48.3 \\
Very high adherence level & 134 & 40.7 \\
Total & 329 & 100.0 \\
\hline
\end{tabular}

\subsection{Relationships Between Social/Family Support and Level of Adherence to ART}

Table 3 below showed the relationship between social and family supports and level of adherence to ART along with its significance. It revealed that among respondents with very low adherence support, little above half of them have high level of adherence to ART, while about 22.9 percent and 19.7 percent of them have very high and low level of adherence respectively. Among respondents with high social and family support, expectedly, 47 percent and 45 percent have high and very high level of adherence respectively to ART with very minute proportion having low level of adherence to ART.

The Pearson's chi-square value was 22.14 . The probability associated with the chi-square statistic of 22.14 was .001 indicating a strong association between family support and level of adherence to ART. Among people with very low level of adherence, $4.9 \%$ had low family support while $3.4 \%$ had high family support.

Table 3. Relationships between social/family support and level of adherence to art.

\begin{tabular}{|c|c|c|c|c|c|}
\hline \multirow{3}{*}{ Level of social/family support } & \multicolumn{5}{|c|}{ Level of Adherence } \\
\hline & Very low & Low & High & Very high & Total \\
\hline & (Freq)\% & $($ Freq)\% & (Freq)\% & (Freq)\% & (Freq) $\%$ \\
\hline Low support & (3) $4.9 \%$ & (12)19.7\% & $(32) 52.5 \%$ & (14)22.9\% & $(61) 100.0 \%$ \\
\hline High support & (9)3.4\% & (12) $4.5 \%$ & $(127) 47.4 \%$ & (120)44.8\% & (268) $100.0 \%$ \\
\hline $\begin{array}{l}\text { Total } \\
\mathrm{x}^{2}=22.14, \mathrm{df}=3, \mathrm{P}=0.01\end{array}$ & (12)3.6\% & $(24) 7.3 \%$ & (159) $48.3 \%$ & (134) $40.7 \%$ & (329) $100.0 \%$ \\
\hline
\end{tabular}

Table 4. Socio-demographic characteristics of Focus Group Discussion Respondents

\begin{tabular}{lll}
\hline Socio-demographic & Frequency $(\mathbf{N}=\mathbf{2 0})$ & Percentage \\
\hline SEX & & \\
Male & 10 & 50.0 \\
Female & 10 & 50.0 \\
AGE & & \\
$28-45$ & 12 & 60.0 \\
\hline
\end{tabular}

\begin{tabular}{lll}
\hline Socio-demographic & Frequency $\mathbf{( N = 2 0 )}$ & Percentage \\
\hline $46-60$ & 8 & 40.0 \\
EDUCATION & & \\
Primary & 6 & 30.0 \\
Secondary & 8 & 40.0 \\
Post-secondary & 6 & 30.0 \\
OCCUPATION & & \\
Civil servant & 4 & 20.0 \\
Artisan & 4 & 20.0 \\
\hline
\end{tabular}




\begin{tabular}{lll}
\hline Socio-demographic & Frequency $\mathbf{( N = 2 0 )}$ & Percentage \\
\hline Trader & 5 & 25.0 \\
Driver & 4 & 20.0 \\
Self-employed & 3 & 15.0 \\
RELIGION & & \\
Christian & 18 & 90.0 \\
Muslim & 2 & 10.0 \\
\hline
\end{tabular}

\subsection{Socio-cultural Factors Influencing Adherence to Art}

\subsubsection{Nutrition}

Adequate intake of good food has been reported by PLWHA as one of social factors militating against adherence to ARV drugs among them.

Extract 18: In-depth Interview with Health Worker (A Nurse)

'Some people do have problem with nutrition and if they are not feeding well it's not good enough for them maybe because of the economic situation of the country, if there is anything we can do to support them nutritionally adherence will be better.'

Extract 19: In-depth Interview with Health Worker (A medical doctor)

'we found out in the clinic that some of them are not well fed as they require adequate and good food has the drugs they take requires them to be eating very well for the good efficacy of the ARV they are taking'

Extract 20: Response from one of the PLWHA

'my problem is with food as it is a bit difficult to get food for me, and I thank God the drugs are free' (FGD1, Female, 42 years)

\subsubsection{Polygyny}

The culture of having more than one wife is a common phenomenon in the area of study hence it was highlighted by the interviewees as one of the barriers to ART among PLWHA.

Extract 21: In-depth Interview with Health Worker (A Nurse)

'there are some women in the polygamous settings that won't disclose to their husband because they don't want the other wives to know and because of that when the man is around they will not use their medication so that the man will not ask why are you using these drugs, what is it for, so with that they are not really adherent and at the end of the day problem will come. In fact, there's a particular woman that refused to disclose to the husband, the first husband died, she married another one and this one discovered after so many years of living together and he just picked the medication and took it away and the drugs are not within her reach, somebody like that cannot use it because the drugs are out of her reach, somebody like that cannot come back to collect, so eventually decided to stay away'

Extract 22: In-depth Interview with Health Worker (A Medical Doctor)

'Polygyny is a very good example, but some of them it can be husband that's first diagnose or later the wife and they do disclose to each other later so as to take the drugs together'

\subsubsection{Transport Fare to the Clinic}

A very strong factor has been adduced to getting finances for transportation to the clinic on their appointment days as could be seen from these excerpts.

Extract 23: Response from one of the PLWHA

'as soon as I collect my salary I set aside my transport fees to this place as I come from a very far place' (FGD2, Female, 42 years)

Extract 24: Response from one of the PLWHA

'the only thing is the transportation fare. Before cd4 count was free but now we pay for cd4 count' (FGD1, Female, 46 years)

Extract 25: Response from one of the PLWHA

'I just struggle to get transport fare when coming for clinic' (FGD2, Female, 33 years)

\subsubsection{Unemployment}

Joblessness or unemployment was also identified as a factor militating against adherence to ART has been reported by health worker:

Extract 26: In-depth Interview with Health Worker (A Nurse)

'Issue of job unemployment is another problem, if they are gainfully employed it will still be better because I met a patient that have defaulted from the clinic one time and he was trying to explain to me that his problem is money and that he goes from one relative to another as he is not gainfully employed'

\subsubsection{Drug Hawkers}

Extract 27: In-depth Interview with Health Worker (A Nurse)

if you stay in the center of the town in the evening even during the day, there are lots of drug vendors using vehicles to advertise drugs claiming that they can cure HIV.'

\subsubsection{Religion}

Most of the respondents interviewed have a strong belief in their faith but despite that, they drew a very sharp line between taking their medication and their religion. Some of them also said that observing fast is no more possible for them so as to adhere very well to the drugs.

Extract 28: Response from one of the PLWHA

'it doesn't stop me from taking my drugs and after all I didn't tell my pastor that I am having HIV and my faith cure it through my drugs because it's God that can help make the drugs to work o.' (FGD1, Female, 42 years)

Extract 29: Response from one of the PLWHA

'as a Baptists we know that HIV is real and we have medical personnel that come to the church for awareness on regular basis. And once you know how to go about it, it cannot kill you so we do sensitized people on it. We belief there is no other thing apart from the medication we are using and with god all things are possible, but one should not tempt god, once you take your medicine and u keep praying to god, it will work together, but that doesn't mean one should leave its medication without taking it. The two work together but finally concentrate on your medicine' (FGD1, 


\section{Female, 52 years)}

Extract 30: Response from one of the PLWHA

'it doesn't antagonize taken this ARV at all and one cannot use religion to cure diseases as HIV is a disease and its only drug that can be used to manage it' (FGD2, Male, 39 years)

However, few respondents were of the strong belief in their religion more than the ARV drugs.

Extract 31: Response from one of the PLWHA

'we are just praying that God will put a full stop to it, the final cure/medicine that we cure it, before I was told malaria was like this and later they find cure to it and I belief because, I didn't die when the illness hold me to the extent that I cannot drink water, immediately I eat I will vomit it then' (FGD1, Male, 50 years)

Excerpts from a nurse informed on the influence of the faith leaders in their adherence:

'In this environment we are so religious and little things like this we will run to our faith leaders so when they go there, maybe the faith leader is not well informed, some we tell them if they can pray and fast their HIV will go but whereas there are some faith leaders that will interact too here and we encourage them here and support them there are some of them that only disclose their status to their pastors and their pastors have been supportive. We counsel faith leaders here we even invite them and have meetings with them'(Nurse)

\subsubsection{Taking Excuse Duty from Work}

As part of factors influencing adherence to ART, the problem of taking excuse form work and informing their coworkers of going to clinic on their appointment days pose a threat to adherence.

Extract 32: Response from one of the PLWHA

'at my work, taking excuse from work' (FGD2, Male, 45 years)

Extract 33: Response from one of the PLWHA

'I don't tell my co-workers but I do leave the whole day for treatment' (FGD1, Male, 60 years)

\subsubsection{Waking up very Early}

In preparing for the clinic days, most respondents affirmed that waking up very early so as to get to clinic on time and not to miss the appointment, they have to deprive themselves of adequate sleep a day prior to their visit

Extract 34: Response from one of the PLWHA

'When it's about few days to come I must wake up very early so as not to miss clinic'. (FGD1, Male, 50 years)

Extract 35: Response from one of the PLWHA

'the only problem is that I have to wake up very early because, here is first come first serve' (FGD1, Male, 44 years)

Extract 36: Response from one of the PLWHA

'I won't sleep well overnight so as to wake up very early' (FGD2, Female, 60 years)

\subsubsection{Factors Enhancing Adherence to Art}

\section{(i). Fear of Death}

As part of reason responsible for not missing their doses and reasons which motivate them to take their drugs regularly, fear of death was noted as most of them don't want to die untimely.

Extract 37: Response from one of the PLWHA

'I don't want to die and there might be resistance and I don't want to die and I want to take care of my children as I have lost my husband to this HIV.' (FGD2, Female, 42 years)

Extract 38: Response from one of the PLWHA

since we have been told not to omit any of our dosages. I still want to live long' (FGD1, Female, 33 years)

Extract 39: Response from one of the PLWHA

'I don't want to die, I want to live long to see my grandchildren' (FGD1, Female, 60 years)

Extract 40: Response from one of the PLWHA

'because we fear death and we don't want to die' (FGD2, Male, 60 years)

\section{(ii). None Availability of Alternative Treatment}

Presently only antiretroviral drugs have been ascertained as the only form of treatment for HIV, this study further revealed this as most respondents do not have any form of alternate therapy in addition to the ART they are seeking.

Extract 41: Response from one of the PLWHA

'I don't take any other thing.' (FGD2, Male, 44 years)

Extract 42: Response from one of the PLWHA

'no, except if I have malaria I just go to chemist to buy palaxin' (FGD1, Female, 46 years)

Extract 43: Response from one of the PLWHA

'not at all. Whenever I have malaria ii will just buy malaria drugs' (FGD1, Male, 50 years)

Extract 44: Response from one of the PLWHA

'I don't seek treatment anywhere else apart from this clinic' (FGD2, Male, 45 years)

\section{(iii). Improvement on Health Status}

Good clinical and physical outcome as could have been seen from the PLWHA among themselves as evident of being compliant with the ARV has greatly motivated them to adhere to their ARV drugs.

Extract 45: Response from one of the PLWHA

'when my symptoms are no more and I'm getting better now than before' (FGD2, Male, 44 years)

Extract 46: Response from one of the PLWHA

'to make me healthy, for my health sake so as to look healthy as I know God will take control' (FGD2, Female, 46 years)

Extract 47: Response from one of the PLWHA

'my health is improving since I have been on it' (FGD1, Female, 40 years).

\section{Discussion of Findings}

The focus of this study was to contribute to the knowledge in the area of socio-cultural factors that influence adherence to antiretroviral therapy among PLWHA in Ile-Ife. It has been pointed out by researchers that for PLWHA to live a long healthy life there must be a very high level of adherence or compliant to the antiretroviral therapy. This is because 
these classes of drugs are the only form of management for HIV presently as there has been no cure for this ailment. The prevalence of adherence to ART in this study was $89.0 \%$. This finding was lower than that conducted by [16] in Ilorin where the adherence prevalence was $92.6 \%$ as low lack of transportation money, travelling and avoiding being seen were the main factors given for non-adherence among them. However, [17] revealed higher prevalence 97.8\% which was more than what this study reported. This probably was attributable to a fairly good knowledge and perception of ART among the respondents. Contrary to [18], the prevalence was low $58.1 \%$ as the adherence was dependent on adverse drug effects and educational level of patients. Poor financial status, medication adverse effects, lack of confidentiality, occupational factors and stigmatization were the major reasons given for non-adherence. The higher prevalence in this present study was attributed to age, ethnicity, educational level, occupation and whom they are living with.

Considering the influence of socio-cultural factors on the adherence to ART, the study found a very high support from family members of PLWHA and their friends as a very strong indicator for adherence with $86.0 \%$ have a high support level from them. It showed a significant association between family/social support and adherence to ART $\left(\chi^{2}=\right.$ $22.4, \mathrm{p}<0.05)$. However, interviews revealed other various socio-cultural factors like nutrition, polygyny, finances for transport fare to the clinic, issues of unemployment, drug hawkers, fasting for religious activity, use of anointing oils, waking up very early for clinic appointments and taking excuses or permissions from duty were all identified as militating factors against adherence to ART. Meanwhile, fear of death, strong family support, non-availability of alternative form of treatment and improvement in health status contributed to their adherence to ART. To support the result from this study, [19] affirmed that perceived health benefits, and family support were the most-reported facilitators to adherence on ART.

A significant statistically relationship was reported between age, ethnicity, level of education, occupational level, whom they live with and adherence level among the respondents. The age group 31-40 years which are within the reproductive age group adhered strongly to ART. Education attainment and level of adherence to ART exhibited a significant statistical relationship $\left(\chi^{2}=26.04, \mathrm{p}<0.05\right)$. Adherence is inversely proportional to educational attainment. At the very high level of adherence response with secondary school educational attainments feature most prominently (45.4\%) closely followed by those with post-secondary educational attainment $(40.9 \%)$. Most of those with low adherence were post-secondary educational attainment. This probably informed them of their awareness and knowledge on their status hence, improved their level of adherence. Medication adherence was found to be significantly associated with non-use of traditional herbal medicine [10], which was supported by the finding from this study as not seeking alternative treatment contributed positively to adherence in this study.
The respondents' religion is also significantly related to their level of adherence to ART $\left(\chi^{2}=16.76, p<0.05\right)$. The traditional religion practitioners featured prominently (50\%) compared with other religious groups. At the very low level of adherence, adherents of the Islam feature more prominently $(12.5 \%)$ than the Christian (1.9\%). This could be attributed to Islam religion which emphasizes on destiny while Christianity focus more on faith healing.

\section{Conclusion}

The study concluded that various social factors like strong family support, fear of death resulted in a very high level of adherence to ART among PLWHA. It was noted that cultural factors like lack of traditional practices i.e. absence of ritual performing and non-use of herbal or alternative medicines were found to be strong facilitators for adherence to ART. It was revealed that a client's adherence level to ART was very high. As part of the factors influencing adherence negatively to adherence were social factors like poor or lack of good nutrition, lack of transportation cost to the clinic, and unemployment status. The cultural factors that constituted adversely to adherence were polygyny, drug hawkers and adverse religion practices (drinking of anointing oils in place of drugs).

\section{References}

[1] UNAIDS, "FACT SHEET - GLOBAL A I DS UPDATE 2019," 2019.

[2] O. A. Okunola, "Antiretroviral Therapy (ART): Evaluation of Art's Perception among People Living with HIV/AIDS in South Western Nigeria," J. AIDS Clin. Res., vol. 08, no. 01, pp. $1-6,2017$.

[3] E. Wilson and I. Sereti, "Immune restoration after antiretroviral therapy: the pitfalls of hasty or incomplete repairs," Immunol Rev, vol. 254, no. 1, pp. 343-354, 2013.

[4] C. Shoko and D. Chikobvu, "A superiority of viral load over CD4 cell count when predicting mortality in HIV patients on therapy," BMC Infect. Dis., vol. 19, no. 169, pp. 1-10, 2019.

[5] S. Wakibi, Z. Ng'ang'a, and G. Mbugua, "Factors associated with non-adherence to highly active antiretroviral therapy in Nairobi, Kenya," AIDS Res. Ther, vol. 8, no. 43, pp. 1-8, 2011.

[6] T. F. F. Ferguson, K. E. S. Tewart, E. F. Unkhouser, J. T. Olson A. O. W. Estfall, and M. S. S. Aag, "Patient-perceived barriers to antiretroviral adherence: associations with race," AIDS Care, vol. 14, no. 5, pp. 607-617, 2002.

[7] D. R. Bangsberg et al., "Adherence to protease inhibitors, HIV-1 viral load, and development of drug resistance in an indigent population," AIDS, vol. 14, pp. 357-366, 2000.

[8] S. A. Iacob, D. G. Iacob, and G. Jugulete, "Improving the adherence to antiretroviral therapy, a difficult but essential task for a successful HIV treatment-clinical points of view and practical considerations," Front. Pharmacol., vol. 8, no. NOV, pp. 1-12, 2017. 
[9] K. Peltzer, N. F. Preez, S. Ramlagan, and J. Anderson, "Antiretroviral treatment adherence among HIV patients in KwaZulu-Natal, South Africa," BMC Public Health, vol. 10, no. 111, pp. 1-10, 2010.

[10] A. O. Oku, E. T. Owoaje, O. K. Ige, and A. Oyo-ita, "Prevalence and determinants of adherence to HAART amongst PLHIV in a tertiary health facility in south-south Nigeria," BMC Infect. Dis., vol. 13, no. 1, p. 1, 2013.

[11] M. Mukhtar-yola, S. Adeleke, D. Gwarzo, and Z. F. Ladan, "Preliminary investigation of adherence to antiretroviral therapy among children in Aminu Kano Teaching Hospital, Nigeria," African J. AIDS Res., vol. 5, no. 2, pp. 141-144, 2009.

[12] G. Ritzer, Ritzer - Contemporary Sociologists. 2008.

[13] D. O. Case, Looking for Information A Survey of Research on Information Seeking. 2007.

[14] W. Max, Methodology of Social Sciences. 2017.

[15] J. D. Fisher, W. A. Fisher, K. R. Amico, and J. J. Harman, “An
Information - Motivation - Behavioral Skills Model of Adherence to Antiretroviral Therapy," Heal. Psychol., vol. 25, no. 4, pp. 462-473, 2006.

[16] C. Anyaike et al., "Adherence to combined antiretroviral therapy (cART) among people living with HIV/AIDS in a tertiary hospital in Ilorin, Nigeria," Pan Afr. Med. J., vol. 32, no. 10, pp. 1-12, 2019.

[17] U. U. Onyeonoro, U. E. Ebenebe, C. C. Ibeh, U. N. Nwamoh, A. U. Ukegbu, and O. F. Emelumadu, "human immunodeficiency virus / acquired immunodeficiency syndrome in a tertiary health facility in South Eastern Nigeria," J. HIV Hum. Reprod., vol. 1, no. 2, pp. 2-7, 2013.

[18] P. O. Erah and J. E. Arute, "Adherence of HIV / AIDS patients to antiretroviral therapy in a tertiary health facility in Benin City," vol. 2, no. 7, pp. 145-152, 2008.

[19] S. P. Wasti, P. Simkhada, J. Randall, J. V Freeman, and E. Van Teijlingen, "Barriers to and Facilitators of Antiretroviral Therapy Adherence in Nepal: A Qualitative Study," vol. 30, no. 4, pp. 410-419, 2012. 